\title{
FOTO-OXIDAÇÃO CATALÍTICA APLICADA AO TRATAMENTO DE EFLUENTES PARA OBTENÇÃO DE ÁGUA PARA REÚSO NA INDÚSTRIA TÊXTIL
}

\section{PHOTOCATALYTIC OXIDATION (PCO) APPLIED TO EFFLUENT TREATMENT TO OBTAIN WATER TO REUSE IN TEXTILE INDUSTRY}

\section{Daiane Cristina Lenhard ${ }^{1}$; Alessandra Zacarias Santos ${ }^{2}$; Verônika Carrer Fontana ${ }^{3}$; Célia Granhen Tavares ${ }^{4}$}

\author{
${ }^{1,2,3,4}$ Departamento de Engenharia Química, Universidade Estadual de Maringá, Av. \\ Colombo 5790, Bloco E46, 87020-900 - Maringá- PR, e-mail: \\ daiane_lenhard@yahoo.com.br; e-mail: alessandrazs@yahoo.com.br; e-mail: \\ vefontana@hotmail.com; e-mail: celia@deq.uem.br
}

\section{RESUMO}

O objetivo principal deste estudo foi avaliar a utilização do processo de fotooxidação catalítica para a descoloração do corante têxtil comercial Preto Intenso e de um efluente têxtil, visando à obtenção de um efluente final próprio para o reuso na indústria. Tanto o corante quanto o efluente foram obtidos em uma lavanderia que tinge roupas de jeans. $\mathrm{O}$ efluente foi caracterizado quanto à Demanda Bioquímica de Oxigênio (DBO), Demanda Química de oxigênio (DQO), cor, turbidez, $\mathrm{pH}$, varredura espectrofotométrica para determinação do comprimento de onda de absorbância máxima no espectro visível e concentração dos íons cloreto $\left(\mathrm{Cl}^{-}\right)$, sulfato $\left(\mathrm{SO}_{4}^{-2}\right)$, nitrato $\left(\mathrm{NO}_{3}{ }^{-}\right)$e fosfato $\left(\mathrm{PO}_{4}^{-2}\right)$. A água de reúso da mesma lavanderia industrial foi coletada e caracterizada da mesma forma que o efluente composto. Os ensaios de foto-oxidação catalítica foram realizados em um reator de filme impregnado com o dióxido de titânio, $\mathrm{TiO}_{2}$. Nos testes foram avaliadas lâmpadas a vapor de mercúrio de 250 e $125 \mathrm{~W}$, e lâmpadas germicidas de $15 \mathrm{~W}$. Os resultados obtidos mostraram uma melhor descoloração do corante do que do efluente têxtil. No entanto, os resultados obtidos para o efluente têxtil podem ser considerados satisfatórios, uma vez que sua cor apresentou-se inferior à cor da água reutilizada atualmente na lavanderia. Os melhores resultados tanto para o corante quanto para o efluente foram obtidos utilizando-se a lâmpada de mercúrio de $250 \mathrm{~W}$ e duas lâmpadas germicidas de $15 \mathrm{~W}$, obtendo-se descolorações acima de $60 \%$ para o efluente e acima de $90 \%$ para o corante, após 6 horas de experimento.

Palavras-chave: Foto-oxidação catalítica. Efluente têxtil. Dióxido de titânio. Reator fotocatalítico de filme. Radiação ultravioleta 


\section{ABSTRACT}

The main objective of this study was to evaluate the photocatalytic oxidation process to decolorize the commercial textile dye Intense Black and a textile effluent, aiming to obtain a final effluent for reuse in the industry. Both dye and textile effluent was obtained in a local laundry that dyes jeans. The textile effluent was characterized as the Biochemical Oxygen Demand (BOD), Chemical Oxygen Demand (COD), color, turbidity, $\mathrm{pH}$, spectrophotometric scanning, to determine the maximum absorbance wavelength in the visible spectrum, and concentration of chloride $\left(\mathrm{Cl}^{-}\right)$, sulfate $\left(\mathrm{SO}_{4}^{-2}\right)$, nitrate $\left(\mathrm{NO}_{3}^{-}\right)$and phosphate $\left(\mathrm{PO}_{4}^{-2}\right)$ ions. A sample of water reused on the same industrial laundry was collected and it was characterized in the same way as the composed effluent. The effluent treatment was accomplished by a photocatalytic oxidation process in a thin-film reactor impregnated with titanium dioxide, $\mathrm{TiO}_{2}$. Mercury-vapor lamps of 250 and $125 \mathrm{~W}$ and germicide lamps of $15 \mathrm{~W}$ were evaluated during the tests. The results of the dye decolorization percentages were greater than the textile effluent ones. However, good results of effluent decolorization were obtained and the final color of the effluent treated was lower than the reuse water color. The best decolorization results were obtained using the $250 \mathrm{~W}$ mercury-vapor lamp and the $15 \mathrm{~W}$ germicide lamps. After 6 hours of experiment, the dye decolorization and the effluent decolorization was over $90 \%$ and $60 \%$, respectively.

Keywords: Photocatalytic oxidation. Textile effluent. Titanium dioxide. Thin-film photocatalytic reactor. Ultraviolet radiation

\section{INTRODUÇÃ̃}

O crescimento populacional e o desenvolvimento industrial acelerado das últimas décadas têm contribuído enormemente para a geração de grande quantidade de resíduos sólidos, líquidos e gasosos. A falta de controle ambiental, principalmente no que diz respeito ao tratamento destes resíduos, implica comprometimento de recursos essenciais à vida, como a água. Ainda se verifica, entretanto, em lenta conscientização com relação à economia de água e ao tratamento dos efluentes para o reuso em processos industriais.

Dentro deste contexto, o setor têxtil se encontra em especial destaque, devido o seu grande parque industrial instalado gerar grandes volumes de efluentes, os quais, quando não corretamente tratados, podem causar sérios problemas de poluição ambiental (KUNZ et al., 2002). Verifica-se grande dificuldade em se tratar esses efluentes, pelo fato de possuírem grandes quantidades de compostos orgânicos, muitos deles recalcitrantes e de estrutura complexa, como corantes, surfactantes e aditivos. Em particular, os corantes são considerados os compostos mais problemáticos, uma vez que são difíceis de serem removidos, possuem alta solubilidade e são pouco biodegradáveis. 
Os efluentes gerados pelas unidades industriais normalmente são tratados por processos físico-químicos e biológicos convencionais (coagulação química e lodos ativados). Estes apresentam bons resultados na remoção de carbono orgânico, mas têm como inconveniente, a alta geração de lodo e a necessidade de grandes áreas para implantação do processo de tratamento, assim como, de aterros sanitários industriais para disposição do lodo (HASSEMER e SENS, 2002).

Um processo alternativo para estes efluentes, que tem sido avaliado recentemente, é a foto-oxidação catalítica. Este processo emprega catalisador óxido ou sistema metal-óxido, que ao ser iluminado com luz ultravioleta (luz UV) ou solar, gera radicais altamente reativos que participam efetivamente da reação e, podem mineralizar compostos orgânicos a formas não tóxicas, como ácidos minerais, $\mathrm{CO}_{2} \mathrm{e}$ $\mathrm{H}_{2} \mathrm{O}$. Este processo tem se mostrado extremamente eficiente na degradação de várias substâncias, inclusive corantes. As pesquisas sobre a decomposição fotocatalítica de diversos tipos de corantes têm apresentado resultados bastante promissores. Além disso, estudos com efluente têxtil real têm revelado que é possível degradá-los completamente ou parcialmente por meio da foto-oxidação catalítica, (MORAES, 1999; KOSITZI et al., 2004, BIZANI et al., 2006).

Recentemente, vários artigos têm sido publicados sobre a aplicação da fotooxidação catalítica na degradação de diversos tipos de corantes, tais como, corantes ácidos, reativos, dispersivos, aromáticos e azo (BEHNAJADY et al., 2006; CHEN et al., 2006; KUMAR e MATHUR, 2006; WANG et al., 2006; BUKALLAH et al., 2007; FAISAL et al., 2007).

Verifica-se, no entanto, uma carência de trabalhos sobre a aplicação de processos de foto-oxidação catalítica para o tratamento de efluentes têxteis reais, uma vez que a maioria dos trabalhos enfoca principalmente a degradação de corantes, ou de efluentes sintéticos. Observa-se ainda que o desenvolvimento de reatores, além da escala de bancada, ainda é restrito (MORAES, 1999; SAUER, 2002; KUNZ et al., 2002).

De acordo com Sauer (2002), reatores fotocatalíticos ainda não têm sido estudados com profundidade e este deverá ser um dos aspectos fundamentais a serem desenvolvidos, para a aplicação eficiente e econômica da foto-oxidação catalítica no tratamento de efluentes industriais. Neste trabalho, foi avaliado o tratamento de uma solução de corante e de efluente de lavanderia industrial, pelo processo de fotooxidação catalítica em reator de filme, utilizando irradiação ultravioleta. O objetivo deste tratamento é a obtenção de um efluente final próprio para reuso em alguns processos da lavanderia industrial. 


\section{MATERIAL E MÉTODOS}

\section{Corante e Efluente Têxteis}

O corante e efluente utilizados neste estudo foram obtidos em lavanderia industrial que tinge roupas prontas de jeans. Nos ensaios com corante foi utilizada uma solução de 0,01 g.L $\mathrm{L}^{-1}$ do corante comercial Preto Intenso.

A amostra do efluente bruto da lavanderia foi composta pela coleta diária de amostras durante um turno de trabalho, por um período de quinze dias. Este efluente foi caracterizado e armazenado sob refrigeração a $4{ }^{\circ} \mathrm{C}$.

Para a caracterização do efluente foram feitas as seguintes análises: cor, turbidez, $\mathrm{pH}$, demanda química de oxigênio (DQO), demanda bioquímica de oxigênio (DBO), concentração dos íons cloretos, sulfato, fosfato e nitrato, bem como varredura espectrofotométrica, para determinação do comprimento de onda de máxima absorbância. A determinação de DQO, DBO e concentração de íons cloreto foram realizadas de acordo com as metodologias descritas no Standard Methods for the Examination of Water and Wastewater (APHA,1998). A concentração dos íons fosfato, nitrato e sulfato foram determinados utilizando-se as metodologias da $\mathrm{HACH}$ Company.

A varredura espectrofotométrica e as leituras de absorbância foram realizadas utilizando o espectrofotômetro CADAS 5000. A determinação de cor e turbidez foram realizadas através do espectrofotômetro $\mathrm{HACH}$, modelo DR/2010.

Também foi coletada uma amostra da água de reuso que vem sendo utilizada pela lavanderia, a qual foi caracterizada da mesma forma que o efluente bruto. Esta água de reuso consiste do efluente gerado pela empresa após ser submetido ao tratamento por processo físico-químico e biológico.

\section{Catalisador e Fixação na Placa de Vidro}

Foi utilizado neste estudo o semicondutor dióxido de titânio, $\mathrm{TiO}_{2}$, na forma anatase, da SIGMA-ALDRICH. A metodologia para fixação do catalisador foi baseada no método descrito por Nogueira e Jardim (1996). Primeiramente, a placa de vidro jateado foi lavada com detergente e ácido nítrico $10 \%$ e seca em estufa a $105^{\circ} \mathrm{C}$ por 15 min. Para imobilização do catalisador foi preparada uma suspensão de $10 \%$ de $\mathrm{TiO}_{2}$ em água destilada, a qual foi passada sobre a placa de vidro, deixando escorrer o excesso por alguns minutos. Em seguida, a placa foi colocada para secar novamente em estufa por 15 minutos a $105{ }^{\circ} \mathrm{C}$. Este procedimento foi repetido de forma a se obter $10 \mathrm{~g}$ de $\mathrm{TiO}_{2}$ por $\mathrm{m}^{2}$ de placa. Após estes procedimentos, a placa com dióxido de titânio foi calcinada em mufla a $300{ }^{\circ} \mathrm{C}$ durante 2 horas.

\section{Ensaios de Degradação}

Os ensaios de degradação foram realizados em reator foto-catalítico de filme, que consiste em uma placa de vidro jateado de dimensão de aproximadamente $30 \times 40$ $\mathrm{cm}$, montada em um suporte que permite que esta se mantenha inclinada favorecendo 
o fluxo natural descendente (Figura 1). Na superfície da placa de vidro foi imobilizado o catalisador conforme procedimento descrito anteriormente. Em todos os ensaios, utilizou-se $1 \mathrm{~L}$ de solução de corante ou de efluente bruto, cuja recirculação foi feita utilizando-se uma bomba peristáltica.

A irradiação ultravioleta foi fornecida por lâmpadas a vapor de mercúrio: de alta pressão de $125 \mathrm{~W}$ ou de $250 \mathrm{~W}$, sem o bulbo de proteção e de baixa pressão (germicidas) de $15 \mathrm{~W}$. As lâmpadas foram posicionadas a $3 \mathrm{~cm}$ da placa de vidro. A placa foi inclinada em $30^{\circ}$, para facilitar o escoamento do líquido. A reação foi realizada à pressão atmosférica e temperatura de $20{ }^{\circ} \mathrm{C}$, mantida por um banho termostatizado. Não foi feito ajuste no $\mathrm{pH}$ do efluente e a vazão de circulação do mesmo pelo reator foi de aproximadamente $17 \mathrm{~L} \cdot \mathrm{h}^{-1}$. A unidade de reação foi isolada do ambiente de modo a não ocorrer vazamento de luz ultravioleta.

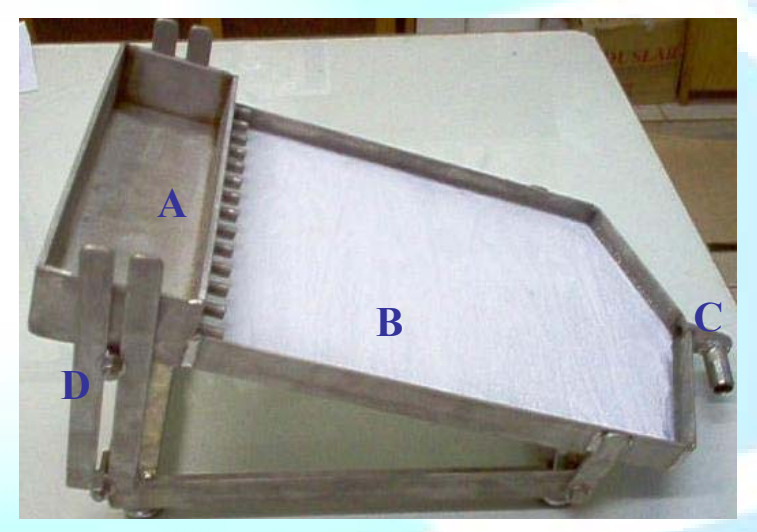

Figura 1. Reator foto-oxidativo de filme; A - Reservatório do líquido para escoamento descendente; $\mathrm{B}$ Placa de vidro com $\mathrm{TiO}_{2}$ imobilizado; C - Saída do líquido (que retorna a "A”); D - Dispositivo de regulagem da inclinação da placa.

Foram retiradas alíquotas de $5 \mathrm{~mL}$ de amostra em determinados tempos de reação $(10,20,30,45,60,90,120,180$ e 240 min.), para realização de varredura espectrofotométrica, de forma a avaliar a descoloração da solução de corante e do efluente. Ao final dos experimentos com efluente, também foi determinada a cor do efluente tratado para comparação com a água de reúso da lavanderia. Foram realizados experimentos controle, com catalisador na ausência de irradiação ultravioleta e na ausência de catalisador com irradiação ultravioleta.

As percentagens de descolorações foram calculadas de acordo com a equação 1, descrita por LENHARD (2010):

$\operatorname{Descoloração~}(\%)=\frac{\left(A b s_{i}-A b s_{f}\right)}{A b s_{i}} \cdot 100$

Em que,

$A b s_{i}=$ Absorbância da solução antes do tratamento

$A b s_{f}=$ Absorbância da solução após o tratamento 
Foi realizado um ajuste cinético dos dados de redução de absorbância das soluções nos comprimentos de onda de máxima absorbância. Para o ajuste de um modelo cinético foi considerada a equação de Langmuir-Hinshelwood (Equação 2), considerando cinética de primeira ordem, para a qual a taxa de reação pode ser escrita de acordo com a Equação 3.

Equação de Langmuir-Hinshelwood:

$r=-\frac{d S}{d t}=\frac{k_{r} K_{a} S}{\left(1+K_{a} S\right)}$

Em que: $\mathrm{k}_{\mathrm{r}}$ : constante de taxa de reação

$\mathrm{K}_{\mathrm{a}}$ : constante de adsorção

$\mathrm{S}:$ concentração do substrato

Ajuste linear para cinética de primeira ordem:

$-\ln \left(\frac{S(t)}{S_{0}}\right)=k_{a p} . t$

Em que: $k_{\text {ap }}$ é a constante cinética aparente de primeira ordem.

\section{RESULTADOS E DISCUSSÃO}

Caracterização do Efluente e da Água de Reúso

A Tabela 1 apresenta as características do efluente e da água de reúso. Tanto ambos as concentrações de DQO e DBO apresentam-se dentro ou próximas ao limite para descarte, estabelecidas pelo Instituto Ambiental do Paraná, (2010) que são de $125 \mathrm{mg} . \mathrm{L}^{-1}$ e $50 \mathrm{mg} . \mathrm{L}^{-1}$, respectivamente. A cor aparente, porém, tanto do efluente quanto da água de reúso, se apresentou superior ao limite de 70 unidades de $\mathrm{Pt} / \mathrm{Co}$, estabelecido para descarte. Este parâmetro é o que merece maior atenção no tratamento do efluente, tanto para descarte quanto para reúso na indústria. 
Tabela 1 - Resultados da caracterização do efluente e da água de reúso.

\begin{tabular}{ccc}
\hline Parâmetro & Efluente & Água de reuso \\
\hline $\mathrm{pH}$ & 7,47 & 7,42 \\
Cor (unidades de $\mathrm{Pt} / \mathrm{Co})$ & 430 & 285 \\
Turbidez $(\mathrm{Fau})$ & 122 & 49 \\
DBO $\left(\mathrm{mgO}_{2} \cdot \mathrm{L}^{-1}\right)$ & 12 & 30 \\
DQO $\left(\mathrm{mgO} \cdot \mathrm{L}^{-1}\right)$ & 150 & 110 \\
Sulfatos $\left(\mathrm{mg} \cdot \mathrm{L}^{-1}\right)$ & 155 & 135 \\
Cloretos $\left(\mathrm{mg} \cdot \mathrm{L}^{-1}\right)$ & 0,235 & 0,242 \\
Fosfatos $\left(\mathrm{mg} \cdot \mathrm{L}^{-1}\right)$ & 0,8 & 0,55 \\
Nitratos $\left(\mathrm{mg} \cdot \mathrm{L}^{-1}\right)$ & 9,15 & 6,85 \\
\hline
\end{tabular}

A varredura espectrofotométrica do efluente indicou um pico de absorbância máxima em $660 \mathrm{~nm}$, de forma que as porcentagens de descoloração do efluente serão determinadas neste comprimento de onda. A água de reuso, no entanto, não apresentou nenhum pico pronunciado no espectro visível, indicando que não há presença pronunciada de compostos coloridos, não degradados, na amostra.

A maior parte dos corantes presentes no efluente bruto da lavanderia é removida pelo processo de coagulação-floculação, sendo que o restante é degradado ou adsorvido pelos microrganismos dos processos biológicos do sistema de tratamento. Os corantes removidos do efluente bruto são concentrados no lodo durante os processos de tratamento.

\section{Ensaios de Degradação}

Os resultados de descoloração do corante comercial Preto Intenso, avaliada no comprimento de onda de $600 \mathrm{~nm}$, estão apresentados na Figura 2. Aqueles do ajuste cinético de primeira ordem da degradação corante, avaliada pela diminuição da absorbância no comprimento de onda de $660 \mathrm{~nm}$, está apresentada na Figura 3. Os parâmetros cinéticos relacionados à taxa de degradação do corante estão apresentados na Tabela 2. 


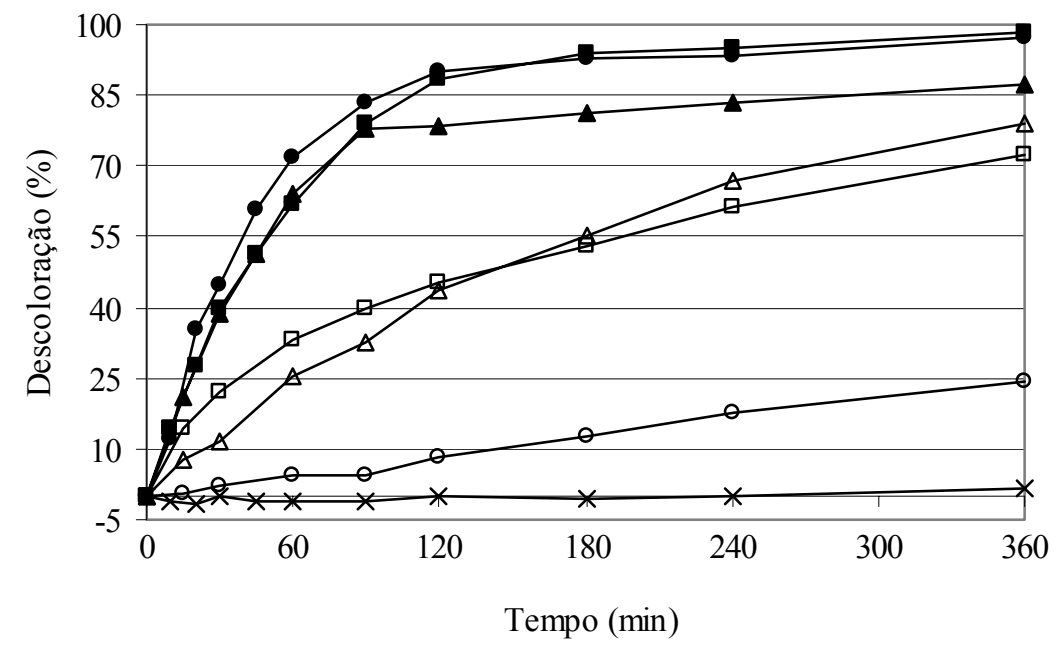

Figura 2. Descoloração do corante preto intenso por processo de foto-oxidação catalítica, utilizando diferentes fontes de radiação ultravioleta: — - Lâmpada de $250 \mathrm{~W}$; $\square$ - Lâmpada de $250 \mathrm{~W}$, sem $\mathrm{TiO}_{2}$; • Lâmpada de $125 \mathrm{~W}$; o - Lâmpada de $125 \mathrm{~W}$, sem $\mathrm{TiO}_{2}$; $\Delta$ - Lâmpada de $15 \mathrm{~W} ; \Delta$ - Lâmpada de $15 \mathrm{~W}$ sem $\mathrm{TiO}_{2} ; \times$ - Sem radiação com $\mathrm{TiO}_{2}$.

De acordo com os resultados apresentados na Figura 2, observou-se que a potência da lâmpada utilizada influenciou na descoloração do corante, somente nos experimentos sem a presença de catalisador. Nos ensaios com catalisador, observouse descoloração após 360 min., próxima a 100\%, utilizando-se as lâmpadas de alta pressão e descoloração inferior (aproximadamente 90\%), utilizando-se a lâmpada de baixa pressão.

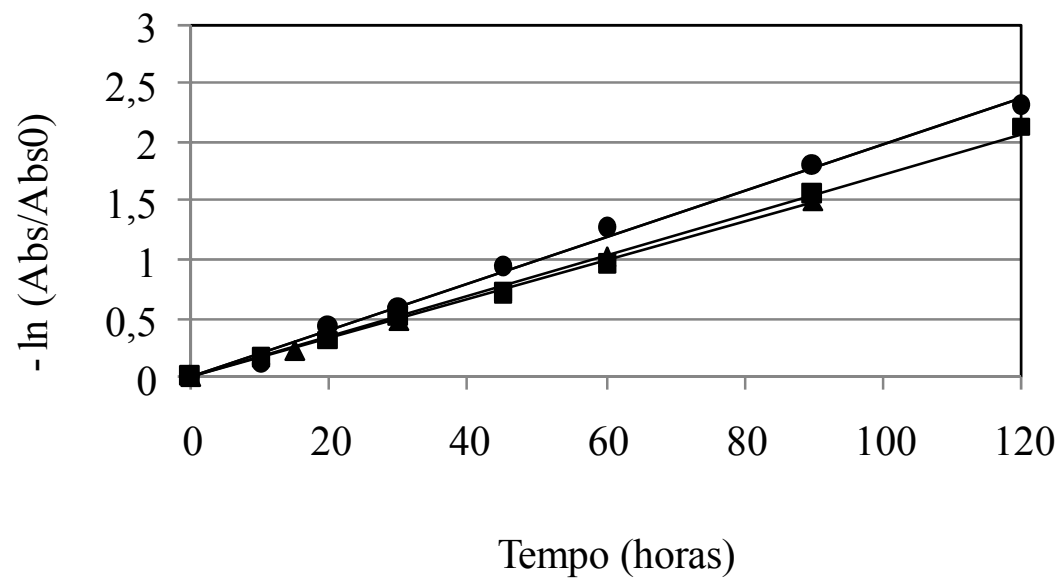

Figura 3. Ajuste dos dados de absorbância, em $600 \mathrm{~nm}$, do corante preto intenso para cinética de primeira ordem; - - Lâmpada de $250 \mathrm{~W}$; • - Lâmpada de $125 \mathrm{~W}$; $\mathbf{\Lambda}$ - Lâmpada de 15 W. 
Tabela 2 - Parâmetros cinéticos da degradação do corante preto intenso.

\begin{tabular}{l|ccc}
\hline $\begin{array}{l}\text { Lâmpada } \\
\text { utilizada }\end{array}$ & $\begin{array}{c}\text { \% Descoloração após } \\
\mathbf{1 2 0} \text { min }\end{array}$ & $\boldsymbol{k}_{a p}\left(\mathbf{m i n}^{-1}\right)$ & $\begin{array}{c}\text { Coeficiente de } \\
\text { correlação }\left(\boldsymbol{R}^{2}\right)\end{array}$ \\
\hline $125 \mathrm{~W}$ & 90,11 & 0,019 & 0,995 \\
$250 \mathrm{~W}$ & 88,333 & 0,017 & 0,995 \\
$15 \mathrm{~W}$ & 78,241 & 0,014 & 0,944 \\
\hline
\end{tabular}

Pelo ajuste cinético verificou-se que, apesar da descoloração final do corante ter sido maior nos ensaios usando-se a lâmpada de $250 \mathrm{~W}$, a cinética de degradação avaliada nos primeiros $120 \mathrm{~min}$. de experimentos foi mais rápida utilizando-se a lâmpada de $125 \mathrm{~W}$, apresentando maior constante cinética $\left(\mathrm{k}_{\mathrm{ap}}\right)$. A cinética de degradação com a lâmpada de baixa pressão de $15 \mathrm{~W}$ se apresentou mais lenta, principalmente devido à queda na taxa de descoloração após 90 min. de reação, como pode ser verificado na Figura 1. Ainda assim, se considera promissor o resultado obtido utilizando-se as lâmpadas de baixa pressão, uma vez que apresentam potência menor do que as de alta pressão e menor consumo de energia.

Segundo Golimowski e Golimowska (1996), citados por Cavicchioli e Gutz (2003), as lâmpadas de baixa pressão são essencialmente monocromáticas com cerca $80 \%$ da emissão em $253 \mathrm{~nm}$, enquanto as lâmpadas de alta pressão apresentam várias bandas alargadas na região UV, sendo os picos em 365, 436 e $546 \mathrm{~nm}$ os mais intensos. Além disso, a eficiência de conversão da potência em radiação UV das lâmpadas de baixa pressão é melhor do que as lâmpadas de média e alta pressão que, apesar de apresentarem potência nominal aproximadamente uma ordem de grandeza maior, convertem em luz UV somente cerca de $30 \%$ da potência elétrica consumida.

Ziolli e Jardim (1998), citaram que para ocorrer a foto-oxidação catalítica é necessário que os elétrons na superfície do catalisador, $\mathrm{TiO}_{2}$, absorvam energia ultravioleta e passem da banda de valência para a de condução, gerando lacuna na banda de valência. Essas lacunas apresentam potenciais suficientemente positivos para gerarem radicais hidroxila, a partir de moléculas de água adsorvidas na superfície do semicondutor, os quais podem, conseqüentemente, oxidar contaminantes orgânicos (SANTANA et al., 2003). Desta forma, a emissão essencialmente em $254 \mathrm{~nm}$ e a maior eficiência de conversão da potência em radiação UV por parte das lâmpadas germicidas, fazem com que estas apresentem eficiências de degradação de compostos orgânicos semelhantes às eficiências obtidas utilizandose lâmpadas de alta pressão.

Nos ensaios sem catalisador, somente com radiação ultravioleta, verificou-se boas taxas de descoloração (acima de 70\%) da solução de corante, utilizando-se lâmpada a vapor de mercúrio de $250 \mathrm{~W}$ e lâmpada germicida de $15 \mathrm{~W}$. Houve grande eficiência na descoloração, também pelo processo de fotólise, o que é justificado pela absorção de radiação ultravioleta pela solução corante provocando a quebra das 
moléculas e, portanto, sua degradação. Os ensaios sem radiação mostraram que não houve descoloração do corante por adsorção no catalisador.

Andronic e Duta (2007), avaliaram a degradação do corante "methyl orange" pelo processo de foto-oxidação catalítica utilizando $\mathrm{TiO}_{2}$ suportado. Utilizando três lâmpadas de $18 \mathrm{~W}$ esses autores verificaram, aproximadamente, $90 \%$ de descoloração de $500 \mathrm{~mL}$ da solução $7,8125 \mathrm{mg} . \mathrm{L}^{-1}$ do corante, após $360 \mathrm{~min}$. de radiação.

A descoloração de uma solução $10 \mathrm{mg} . \mathrm{L}^{-1}$ do corante Basic Red 46 (BR 46), utilizando $\mathrm{TiO}_{2}$ suportado em fibra de celulose, foi avaliada por Mounir et al. (2007). Estes utilizaram como fonte de radiação ultravioleta, duas lâmpadas de $15 \mathrm{~W}$ cada uma e obtiveram $90 \%$ de descoloração do corante após 2 horas de radiação ultravioleta. Estes resultados foram inferiores àqueles aqui obtidos, pois se verificou que $80 \%$ de descoloração de $1000 \mathrm{~mL}$ da solução $10 \mathrm{mg} . \mathrm{L}^{-1}$ do corante comercial Preto Intenso, alcançada após 2 horas de radiação ultravioleta e utilizando-se apenas uma lâmpada de $15 \mathrm{~W}$. Provavelmente, isto se deve também às diferenças estruturais dos corantes avaliados nos trabalhos citados. Além disso, a distância entre a lâmpada e a lâmina de efluente sobre a placa com catalisador e a espessura da lâmina de efluente pode ter favorecido o contato da radiação com o catalisador e as moléculas de corante, favorecendo o processo de descoloração.

Verifica-se que os resultados obtidos neste estudo apresentaram-se bastante promissores, principalmente no que diz respeito ao uso de lâmpadas germicidas, que são em geral mais duradouras e consomem menos energia do que as lâmpadas convencionais a vapor de mercúrio, e apresentaram eficiência semelhante. Deve-se procurar, no entanto, aperfeiçoar o tratamento de forma a aumentar a eficiência do processo, minimizando o tempo de reação.

Os resultados de descoloração do efluente têxtil, em função do tempo, utilizando lâmpadas a vapor de mercúrio de alta pressão $(250$ e $125 \mathrm{~W})$ e de baixa pressão (15 W), estão apresentados nas Figuras 4 e 5, respectivamente.

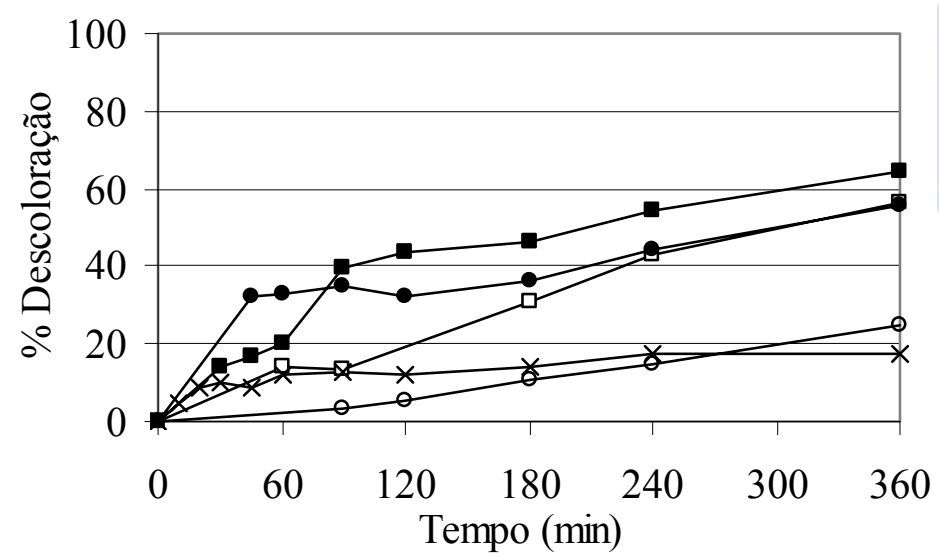

Figura 4. Descoloração de efluente têxtil pelo processo de foto-oxidação catalítica utilizando lâmpadas a vapor de mercúrio: - - Lâmpada de $250 \mathrm{~W}$; $\square$ - Lâmpada de $250 \mathrm{~W}$, sem $\mathrm{TiO}_{2}$; • - Lâmpada de $125 \mathrm{~W}$; ○ Lâmpada de $125 \mathrm{~W}$, sem $\mathrm{TiO}_{2} ; \times$ - Sem radiação com $\mathrm{TiO}_{2}$. 


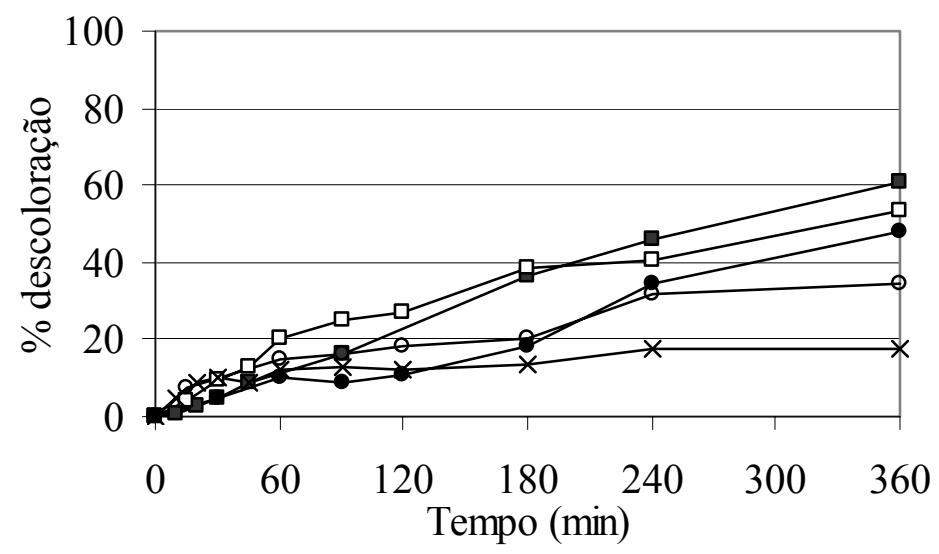

Figura 5. Descoloração de efluente têxtil pelo processo de foto-oxidação catalítica utilizando lâmpadas germicidas: - - 2 Lâmpadas de $15 \mathrm{~W}$; $\square-2$ Lâmpadas de $15 \mathrm{~W}$, sem $\mathrm{TiO}_{2} ; \bullet-1$ Lâmpada de $15 \mathrm{~W}$; ○ - 1

Lâmpada de $15 \mathrm{~W}$, sem $\mathrm{TiO}_{2} ; \times$ - Sem radiação com $\mathrm{TiO}_{2}$.

Os resultados mostram descoloração superior a 50\%, após 360 min. de experimento, para todas as lâmpadas avaliadas. Verifica-se, que a constante cinética de degradação do efluente apresentou-se semelhante para as diversas lâmpadas utilizadas, sendo que aquela baixa pressão apresenta a vantagem de consumirem menos energia por apresentarem menor potência Tabela 3.

Tabela 3 - Parâmetros cinéticos da descoloração do efluente

\begin{tabular}{l|ccc}
\hline $\begin{array}{l}\text { Lâmpada } \\
\text { utilizada }\end{array}$ & $\begin{array}{c}\text { \% Descoloração após } \\
\mathbf{3 6 0} \text { min }\end{array}$ & $\boldsymbol{K}\left(\mathbf{m i n}^{-1}\right)$ & $\begin{array}{c}\text { Coeficiente de } \\
\text { correlação }\left(\boldsymbol{R}^{2}\right)\end{array}$ \\
\hline $125 \mathrm{~W}$ & 55,596 & 0,003 & 0,963 \\
$250 \mathrm{~W}$ & 64,260 & 0,002 & 0,911 \\
$1 \times 15 \mathrm{~W}$ & 48,182 & 0,001 & 0,924 \\
$2 \times 15 \mathrm{~W}$ & 60,577 & 0,002 & 0,978 \\
\hline
\end{tabular}

Com exceção do teste com a lâmpada de $125 \mathrm{~W}$, as descolorações obtidas sem catalisador foram semelhantes às obtidas nos testes com catalisador, indicando que há grande absorção da radiação ultravioleta da lâmpada pelo efluente, provocando a quebra de moléculas presentes no mesmo, resultando na degradação por fotólise direta. O experimento controle sem radiação e com catalisador apresentou uma descoloração inferior a $20 \%$. Acredita-se que esta pequena redução de cor seja devida à adsorção no catalisador.

Na Figura 6 estão apresentados os ajustes cinéticos de degradação do efluente no comprimento de onda de $660 \mathrm{~nm}$. Os parâmetros cinéticos relacionados à taxa de degradação do corante estão apresentados na Tabela 3 . Tanto as taxas de 
descoloração como as constantes cinéticas de reação indicaram uma eficiência inferior na degradação do efluente comparada à do corante preto intenso, indicando que a velocidade degradação do efluente é muito mais lenta.

Provavelmente, este resultado decorreu devido à presença de diversos compostos orgânicos no efluente, além do corante preto intenso, inclusive outros corantes que, quando misturados, podem dificultar o processo de degradação.

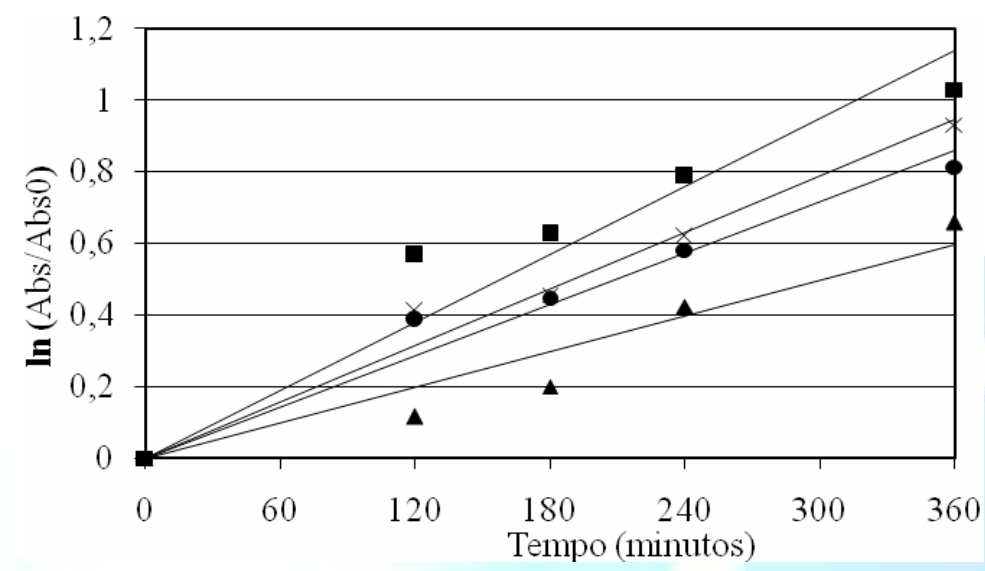

Figura 6. Ajuste dos dados de absorbância do efluente para uma cinética de primeira ordem.

Além disso, pela caracterização do efluente aqui estudado foi verificada a presença de íons sulfato, fosfato, cloreto e nitrato, os quais, segundo Legrini et al. (1993) e Habibi et al. (2005), podem influenciar negativamente no processo de fotooxidação catalítica, devido à adsorção destes íons nos sítios ativos do catalisador, diminuindo a sua eficiência. Isto justifica também o fato dos resultados obtidos sem catalisador terem sido semelhantes aos resultados utilizando catalisador.

A utilização da foto-oxidação catalítica no tratamento de efluente têxtil foi recentemente avaliada por Bizani et al. (2006). A completa descoloração do efluente foi alcançada após $6 \mathrm{~h}$, mas a redução de toxicidade do mesmo foi somente alcançada parcialmente (aproximadamente $35 \%$ em $6 \mathrm{~h}$ de tratamento). Apesar da eficiência alcançada por esses autores na descoloração do efluente ter sido maior do que os resultados aqui observados. Acredita-se que isto decorreu dos mesmos terem usados catalisador em suspensão, enquanto que neste estudo foi utilizado $\mathrm{TiO}_{2}$ suportado sobre uma placa de vidro.

Segundo Rachel et al. (2002), apud Mascolo et al. (2007), a fixação do $\mathrm{TiO}_{2}$ em suportes sólidos geralmente reduz a eficiência do processo fotocatalítico, como conseqüência da redução da área superficial do catalisador suportado em relação ao catalisador em suspensão.

Mascolo et al. (2007) avaliaram a eficiência da foto-oxidação catalítica utilizando $\mathrm{TiO}_{2}$ suportado e em suspensão na degradação do corante "metil vermelho". Esses autores verificaram melhor eficiência usando catalisador em 
suspensão e atribuíram que esse resultado deve-se a maior superfície de contato do catalisador com a solução.

Os resultados da determinação de cor aparente do efluente, após 6 horas de tratamento, estão apresentados na Tabela 4.

Tabela 4 - Resultados de cor aparente do efluente, após 6h de tratamento, utilizando diferentes fontes de radiação UV.

\begin{tabular}{c|c}
\hline Fonte de radiação ultravioleta & $\begin{array}{c}\text { Cor aparente final do efluente } \\
\text { (unidades de Pt/Co) }\end{array}$ \\
\hline Lâmpada $250 \mathrm{~W}$ & 116 \\
Lâmpada $125 \mathrm{~W}$ & 105 \\
Duas Lâmpadas $15 \mathrm{~W}$ & 54 \\
Uma Lâmpada $15 \mathrm{~W}$ & 84 \\
\hline
\end{tabular}

Verifica-se que a cor do efluente tratado por todos os processos propostos foi inferior àquela da água de reuso, atualmente utilizada pela lavanderia, cujo valor obtido foi de 285 unidades de Pt/Co, conforme previamente apresentado na Tabela 1 , demonstrando portanto, o potencial do processo de foto-oxidação catalítica para a remoção de cor de efluentes têxteis, principalmente quando a intenção é o reuso na lavanderia. Quando se trata de tratamento para o descarte do efluente tratado, o processo precisa ser aprimorado para se obter uma cor do efluente tratado inferior a 70 unidades de $\mathrm{Pt} / \mathrm{Co}$, que é o valor exigido pelo órgão ambiental.

\section{CONCLUSÕES}

O processo de foto-oxidação catalítica, utilizando catalisador imobilizado, apresentou-se promissor no tratamento de efluentes têxteis. $\mathrm{O}$ processo foi mais eficiente para a degradação do corante preto intenso do que para o efluente real. A descoloração deste último foi satisfatória permitindo a obtenção de um efluente final com coloração apropriada para o reuso na indústria. As lâmpadas a vapor de mercúrio de baixa pressão (germicidas) apresentaram eficiência semelhante às lâmpadas de maior potência, apresentando potencial para substituir estas últimas em função da vantagem econômica de consumirem menos energia. Outras configurações de reatores deverão ser avaliadas, a fim de se aperfeiçoar o processo de foto-oxidação catalítica de efluentes reais. 


\section{REFERÊNCIAS}

ANDRONIC, L.; DUTA, A. TiO 2 thin films for dyes photodegradation. Thin Solid Films, USA, v. 515, p. 6294-6297, 2007.

APHA-AMERICAN PUBLIC HEALTH ASSOCIATION. Standard methods for the examination of water and wastewater. 20 ed. Washington: American Public Health Association, AWWA, WPCF, 1998. 1569 p.

BEHNAJADY, M.A.; MODIRSHAHLA, N.; HAMZAVI, R. Kinetic study on photocatalytic degradation of C.I. Acid Yellow 23 by $\mathrm{ZnO}$ photocatalyst. Journal of Hazardous Materials, Amsterdam, v. 133, p. 226-232, 2006.

BIZANI, E.; FYTIANOS, K.; POULIOS, I.;TSIRIDIS, V. Photocatalytic decolorization and degradation of dye solutions and wastewaters in the presence of titanium dioxide. Journal of Hazardous Materials, Amsterdam, v. 136, n. 1, p. 8594, 2006.

CAVICCHIOLI, A.; GUTZ, I.G.R. O uso de radiação ultravioleta para o prétratamento de amostras em análise inorgânica, Química Nova, São Paulo v. 6, n.6, 2003.

CHEN, C.; LU, C.; CHUNG, Y. Photocatalytic degradation of ethyl violet in aqueous solution mediated by $\mathrm{TiO}_{2}$ suspensions, Journal of Photochemistry and

Photobiology A: Chemistry, Japan, v. 181, p 120-125, 2006.

HABIBI, M. H.; HASSANHADEH, A.; MAHDAVI, S. The effect of operational parameters on the photocatalytic degradation of three textile dyes in aqueous $\mathrm{TiO}_{2}$ suspensions. Journal of photochemistry and photobiology A: chemistry, Japan, v. 172, p. 89-96, 2005.

HASSEMER, M.E.N.; SENS, M.L. Tratamento do efluente de uma indústria têxtil. Tratamento físico-químico com ozônio e coagulação/floculação. Engenharia Sanitária e Ambiental, Rio de Janeiro, v. 7, n. 1-2, p. 30-36, 2002.

IAP - INSTITUTO AMBIENTAL DO PARANÁ. Curitiba - PR. Disponível em: www.iap.pr.gov.br. Acesso em: 23 set. 2010.

KOSITZI, M., ANTONIADIS, A., POULIOS, I., KIRIDIS, I., MALATO, S. Solar photocatalytic treatment of simulated dyestuff effluents. Solar Energy.USA, v. 77, p.591-600, 2004. 
KUMAR, A., MATHUR, N. Photocatalytic degradation of aniline at the interface of $\mathrm{TiO} 2$ suspensions containing carbonate íons. Journal of Colloid and Interface Science, USA, v. 300, p. 244-252, 2006.

KUNZ, A.; PERALTA-ZAMORA, P.; MORAES, S. G. DE; DURAN, N. Novas tendências no tratamento de efluentes têxteis, Química Nova, São Paulo, v. 25. p.78$82,2002$.

LEGRINI, O.; OLIVEROS, E.; BRAUN, A.M. Photochemical processes for water treatment. Chemical Reviews, Colorado, v.93, n.2, p.671-698, 1993.

LENHARD, D.C. Tratamento de efluentes têxteis em reatores foto-oxidativos. 2010.152f. Tese (Doutorado em Engenharia Química) - Programa de Pós-Graduação em Engenharia Química. Universidade Estadual de Maringá. Maringá. 2010.

MASCOLO, G.; COMPARELLI, R.; CURRI, M.L.; LOVECCHIO, G.; LOPEZ, A.; AGOSTIANO, A. Photocatalytic degradation of methil red by $\mathrm{TiO}_{2}$ : comparison of the efficiency of imobilized nanoparticle versus conventional suspended catalyst. Journal of Hazardous Materials, Amsterdam, v. 142, p. 130-137, 2007.

MORAES, S.G. Processo fotocatalítico combinado com sistemas biológicos no tratamento de efluentes têxteis. 1999.141f. Tese (Doutorado em Química) Instituto de Química. Universidade Estadual de Campinas. Campinas. 1999.

MOUNIR, B.; PON, M.N.; ZAHRAA, O.; YAACOUBI, A.; BENHARAMOU, A. Discoloration of red cationic dye by supported $\mathrm{TiO}_{2}$ photocatalysis. Journal of Hazardous Materials, Amsterdam, v. 148, n. 3, p. 513-520, 2007.

NOGUEIRA, R.F.P.; JARDIM, W.F., A fotocatálise heterogênea e sua aplicação ambiental., Química Nova, São Paulo v. 21. p.69-72. 1998.

SANTANA, H., BONANCÊA, C.E., TAKASHIMA, K. Fotocatálise eletroquímica de atrazina sobre dióxido de titânio: efeito de diferentes parâmetros experimentais.. Química Nova, São Paulo v. 26. p.807-811, 2003..

SAUER, T. Degradação fotocatalítca de corante e efluente têxtil. 2002. 108f. Dissertação (Mestrado em Engenharia Química) - Centro Tecnológico. Departamento de Engenharia Química e Alimentos. Universidade de Santa Catarina, Florianópolis, 2002. 
WANG, Z.; JIANG, T.; DU, Y.; CHEN. K.; YIN, H. Syntesis of mesoporous titania and the photocatalytic activity for decomposition of methyl orange. Materials

Letters, Erlangen, Germany, v. 60, p. 2493-2496, 2006.

ZIOLLI, R.L.; JARDIM, W.F. Mecanismo de fotodegradação de compostos orgânicos, catalisada por $\mathrm{TiO}_{2}$. São Paulo, Química Nova. v. 21. p. 319-325, 1998. 